\title{
PET and movement disorders
}

\author{
DAVID J BROOKS, RICHARD SJ FRACKOWIAK
}

From the MRC Cyclotron Unit, Hammersmith Hospital and Institute of Neurology, National Hospital for Nervous Diseases, London, UK

SUMMARY In this paper the use of PET for determining the patterns of disruption of both regional cerebral metabolism, and the pre- and post-synaptic dopaminergic systems, associated with movement disorders is reviewed. That the various akinetic-rigid syndromes result in distinctive PET findings is shown, making functional imaging valuable in their differential diagnosis. PET may also be useful for detecting the presence of sub-clinical disease in Huntingdon's disease and other inherited movement disorders.

Positron emission tomography (PET) provides a noninvasive means of quantitatively measuring regional cerebral energy metabolism and blood flow, and of assessing the integrity of a number of neurotransmitter systems in patients. As such it is ideally suited for the study of the effects of cerebral diseases associated with movement disorders on regional cerebral function. We have been involved in PET studies on patients with movement disorders through collaboration with Professor CD Marsden and his clinical colleagues, initially at The Maudsley Hospital and Institute of Psychiatry, and more recently at the Institute of Neurology and National Hospitals. In this paper we intend to review the various patterns of regional cerebral metabolic changes associated with akinetic rigid syndromes and the dystonias. We will also discuss disturbances of the integrity of the dopaminergic system that have been detected with PET tracers in movement disorders. Finally, we will consider the future use of PET to study disturbances in the normal patterns of regional cerebral activation in diseases presenting with disorders of movement.

In order to make measurements with PET a tracer tagged with a positron-emitting isotope is administered to a subject either intravenously, or by inhalation. The subject is then scanned, and axial tomographic slices of regional cerebral tracer accumulation are obtained. This tracer accumulation can be related to cerebral metabolism, blood flow, or binding site concentrations by appropriate mathematical models. Positron-emitting isotopes include ${ }^{15} \mathrm{O},{ }^{11} \mathrm{C},{ }^{18} \mathrm{~F}$, and ${ }^{76} \mathrm{Br}$. These are short lived and prepared on-site by a cyclotron. Molecules suitable for use as a PET tracer

Address for reprint requests: Dr D J Brooks, MRC Cyclotron Unit, Hammersmith Hospital W12 0HS, London, UK.

Accepted January 1989
Table 1 PET tracers used in PET studies of movement disorders

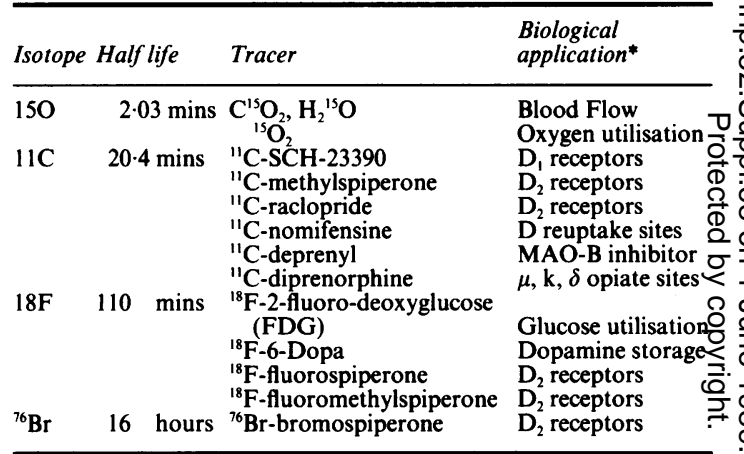

${ }^{*} \mathrm{D}=$ Dopamine. MAO = Monoamine oxidase.

can then be labelled with these isotopes. Table 1 details some PET tracers commonly used in the study of movement disorders.

To data, the PET studies performed on patients with a movement disorder have fallen into two main categories: First, under resting conditions, the changes in regional cerebral metabolism and blood flow associated with Parkinson's disease, progressive supranuclear palsy, multiple system atrophy, Huntingdon's chorea, dystonia, and Wilson's disease have been reported. These changes make it possible, to a major extent, to distinguish between these various diseases and to detect sub-clinically affected patients with Huntingdon's disease. Secondly, PET has been used to assess the integrity of the pre-and post-synaptic components of the dopaminergic system in the above movement disorders. These disrupt the nigrostriatal and efferent striatal pathways in different ways, and so produce varying patterns of dysfunction of the dopaminergic system. The findings of these various PET studies are reviewed below. 
Regional cerebral metabolic changes in movement disorders

(a) Parkinson's disease

The pathology of Parkinson's disease is Lewy body associated degeneration of the substantia nigra compacta and other pigmented brain stem nuclei. The majority of Parkinson's disease patients have normal intellectual function, but those $20 \%$ that have dementia may show degeneration of the nucleus basalis of Meynert (NBM), Alzheimer-like changes, or cortical Lewy body disease at necropsy. There have been a number of PET studies on regional cerebral metabolism and blood flow in Parkinson's disease. Using ${ }^{18} \mathrm{FDG}$, it has been shown that in clinically bilateral Parkinson's disease, striatal glucose utilisation is generally normal. ${ }^{12}$ Cortical glucose utilisation, however, tends to be globally reduced and may shown an Alzheimer-type pattern of disruption, with the posterior parietal cortex being most affected. ${ }^{2}$ Rougemont et $a^{3}$ showed that in spite of a good clinical response to levodopa, Parkinson's disease patients did not show a significant change in their striatal or cortical glucose utilisation following therapy. This lack of change in striatal glucose utilisation after levodopa is not surprising. ${ }^{18}$ FDG uptake primarily reflects activity of synaptic terminals. As dopaminergic terminals make up only $10 \%$ of striatal neurons, even a $50 \%$ increase in dopaminergic function will only result in a $5 \%$ increase in striatal energy utilisation. Such a change in striatal glucose utilisation would be difficult to detect with PET.

In animals, lesioning the nigra results in a transient rise in pallidal glucose utilisation which persists for about three months. ${ }^{4}$ This is thought to reflect increased activity in strio-pallidal efferents as a result of release from the inhibitory effects of the nigrostriatal system. Miletich et $\mathrm{al}^{5}$ have shown that in patients with hemiparkinsonism, early into their disease, utilisation of glucose is raised in the contralateral lenticular nucleus, presumably as a consequence of similar strio-pallidal disinhibition.

Wolfson et $a l^{6}$ have studied regional cerebral oxygen utilisation $\left(\mathrm{rCMRO}_{2}\right)$ and blood flow (rCBF) in patients unilaterally and bilaterally affected by Parkinson's disease. In the bilaterally affected subjects both mean striatal and cortical oxygen utilisation were depressed by $7-10 \%$, while rCBF was depressed by $20 \%$. The Alzheimer-like pattern of posterior parietal metabolic dysfunction in Parkinson's disease noted by Kuhl et al, ${ }^{2}$ was not seen by Wolfson et al, who found a global depression of cortical function. Such global depression would be more likely to result from loss of function of the nucleus basalis of Meynert, with its diffuse cortical projections, than from Alzheimer's disease. By contrast, unilaterally affected Parkinson's disease patients, with early disease, showed a mean increase of $12 \%$ in contralateral basal ganglia oxygen utilisation. This finding is reminiscent of the increased contralateral striatal rCMRGlu reported by Miletich et $a l^{5}$ in his hemiparkinsonian group, and again suggestive of the initial presence of strio-pallidal disinhibition in Parkinson's disease. Interestingly contralateral frontal cortical $\mathrm{rCMRO}_{2}$ and $\mathrm{rCBF}$ were focally depressed in Wolfson's patients with unilateral disease suggesting that selective disruption of the mesofrontal projection fibres had also occurred. Perlmutter et $^{\mathrm{al}}{ }^{7}$ reported a similar depression of contralateral mesofrontal cortex rCBF in the group of eleven patients with hemiparkinsonism.

As with regional cerebral glucose utilisation, ${ }^{3}$ levodopa therapy appeared to have little effect on cerebral oxygen utilisation in Parkinson's disease in spite of a good clinical response to treatment. ${ }^{8}$ There is debate, however, about the effects of levodopa therapy on rCBF. Permutter and Raichle ${ }^{7}$ found no change in mean rCBF after treatment, whereas Leenders $e t a l^{8}$ using higher doses of medication, have reported global increases in $\mathrm{rCBF}$ within one hour of receiving oral levodopa. Subsequently rCBF fell to normal after several weeks of therapy, however, in spite of a continued clinical response to levodopa. This finding, and the observation that the levodopa induced rCBF increases could be blocked by prior administration of domperidone, a peripheral dopamine receptor blocker, suggests that the blood flow increases following levodopa administration are the result of a peripheral action of levodopa on cerebral vasculature.

To summarise, the metabolism of the basal ganglia is normal, or slightly depressed, in patients with bilateral Parkinson's disease, while contra-lateral basal ganglia metabolism may be increased in unilaterally affected patients with early disease. Cortical function is globally depressed, the medial frontal and posterior parietal areas being particularly affected. Levodopa therapy has no significant effect on cortical or striatal metabolism at clinically effective doses.

\section{(b) Huntingdon's disease (HD)}

The pathology of HD consists of fall-out of spiny neurones from the striatum, pallidum, and dentate nuclei. Patients present with chorea, an akinetic-rigid syndrome, and a so-called subcortical dementia where memory and concentration are impaired in the absence of significant apraxia or agnosia. CT brain scans are normal in early disease, but later show atrophy of the heads of the caudate nuclei and frontal cortex.

Several PET studies of regional cerebral glucose utilisation in patients with HD have been reported. Kuhl et $a l^{9}$ first demonstrated reduced caudate rCMRGlu in early HD in the absence of caudate atrophy on CT. Their subjects who were not demented had normal cortical glucose utilisation, but those with 
dementia showed a reduction in the frontal:parietal rCMRGlu ratios. These authors also studied PET in 15 subjects at-risk of HD with PET. Six out of fifteen had abnormally low levels of striatal glucose utilisation, in the absence of clinical findings. Hayden et al ${ }^{10}$ confirmed the presence of reduced caudate rCMRGlu in early HD subjects with chorea but who had a normal CT. Young et al " showed that fall-off of both caudate and putamen glucose utilisation correlated with the degree of locomotor dysfunction in HD. Like Kuhl et al, ${ }^{9}$ these authors found that cortical and thalamic glucose utilisation were normal in nondemented HD patients. Leenders et $a l^{12}$ have shown that not only glucose, but also oxygen utilisation is reduced in the striatum and frontal cortex in HD.

Three groups have studied the predictive value of finding a lowered caudate glucose utilisation in a subject at risk of HD. Mazziotta et al ${ }^{14}$ studied 58 "at risk" subjects, each of whom had a normal CT. Thirty one percent of their subjects had low caudate glucose utilisation, as compared wth $34 \%$ who were predicted to carry the HD gene from DNA polymorphism studies. This represented a $91 \%$ concordance rate. Four at-risk subjects, each with abnormal PET findings, subsequently developed clinical HD, whereas none of their at-risk subjects with normal PET have to date developed symptoms. Using DNA polymorphism studies, Hayden et $a l^{13}$ identified eight subjects at risk for HD who had a $90 \%$ chance of carrying the HD gene. Three of these eight high risk subjects had subnormal levels of caudate glucose utilisation. One out of five "low-risk" subjects, who had only a $5 \%$ chance of carrying the HD gene, also had low caudate metabolism, however. This finding raises some questions about the use of PET studies of caudate glucose utilisation as a means of detecting sub-clinical HD in "at-risk" subjects. Young et al $^{49}$ were unable to demonstrate any significant difference in mean rate of glucose utilisation in the caudate between 29 subjects at risk for HD, and 28 age-matched controls. The scatter in their normal data, however, was far larger than that of Mazziotta et al..$^{14}$

Is a finding of low caudate metabolism specific for chorea? Suchowersky et $a l^{15}$ have shown relatively lowered caudate: thalamic ratios of glucose utilisation in three subjects with benign familial chorea. By contrast striatal glucose utilisation was found to be elevated in four patients with chorea associated with systemic lupus erythematosus. ${ }^{16} \mathrm{Pahl}$ et al ${ }^{17}$ compared PET findings in subjects with tardive dyskinesia (TD) and subjects with HD. In TD cases striatal and thalamic glucose utilisation were elevated, whereas HD patients had depressed striatal rCMRGlu. It must be concluded, therefore, that caudate metabolism may be low, normal, or raised in chorea, and low caudate metabolism in HD reflects the disease pathology rather than the presence of chorea per se. Indeed it has been shown that subjects with HD who have mild psychiatric manifestations alone may have reduced caudate glucose utilisation.

To summarise, HD is characterised by striking caudate hypometabolism, even in the absence of caudate atrophy on CT. Striatal hypometabolism correlates with degree of locomotor dysfunction. Among subjects "at risk" of HD there is a $38 \%-91 \%$ concordance between demonstration of an abnormal PET scan and the identification of subjects carrying the HD gene using DNA polymorphism studies.

\section{(c) Progressive supranuclear palsy (PSP)}

PSP, or Steele-Richardson-Olszewski (SRO) syndrome, is characterised clinically by axial rigidity, a supranuclear vertical gaze palsy, striatal bulbar dysfunction, and "sub-cortical" dementia. Pathologically, neuronal fall-out and neurofibrillary tangles with straight filaments are found in the basal ganglia, cerebellar, and brain-stem nuclei. The cerebral cortex appears to be spared. PSP can be very difficult to diagnose with certainty on clinical grounds alone as a variety of other conditions such as multiple system atrophy, Creuzfeld-Jakob disease, encephalitis lethargica, sub-cortical gliosis, corticobasal degeneration, and multi-infarct disease, can all produce akineticrigid syndromes with supranuclear gaze palsies. "Sub- $\varrho$ cortical" dementias can also be mimicked by early Pick's and Alzheimer's disease, and isolated thalamico and caudate lesions. As a consequence most PETO studies on PSP await pathological validation.

D'Antona et $a l^{18}$ compared the regional cerebral glucose utilisation of six PSP subjects with that of eight controls. The PSP subjects showed a significant reduction of mean frontal cortical metabolism, with lesser reductions of rCMRGlu in other cortical areas. Two of their six subjects, however, did not clearly have PSP as these patients had only mild akinetic-rigid syndromes and isolated restriction of up-gaze in association with their dementia of subcortical type. This illustrates the difficulty in making a clinical diagnosis of PSP. Leenders et al ${ }^{19}$ measured regional cerebral blood flow and oxygen utilisation in five patients with probable PSP. The CBF images of one of their patients are shown in Fig 1. Like D'Antona et al ${ }^{18}$ these workers found a global decrease in cortical metabolism, the frontal cortex being most severely affected. The degree of frontal cortical hypometabolism correlated with disease duration, but not with individual patient's WAIS scores.

Foster et $a l^{20}$ used PET to study 14 subjects probably affected by PSP. Glucose utilisation was significantly reduced in the striatum, thalamus, and pons, and in all cortical regions, but particularly the frontal region. Cerebellar function was spared. Clin- 


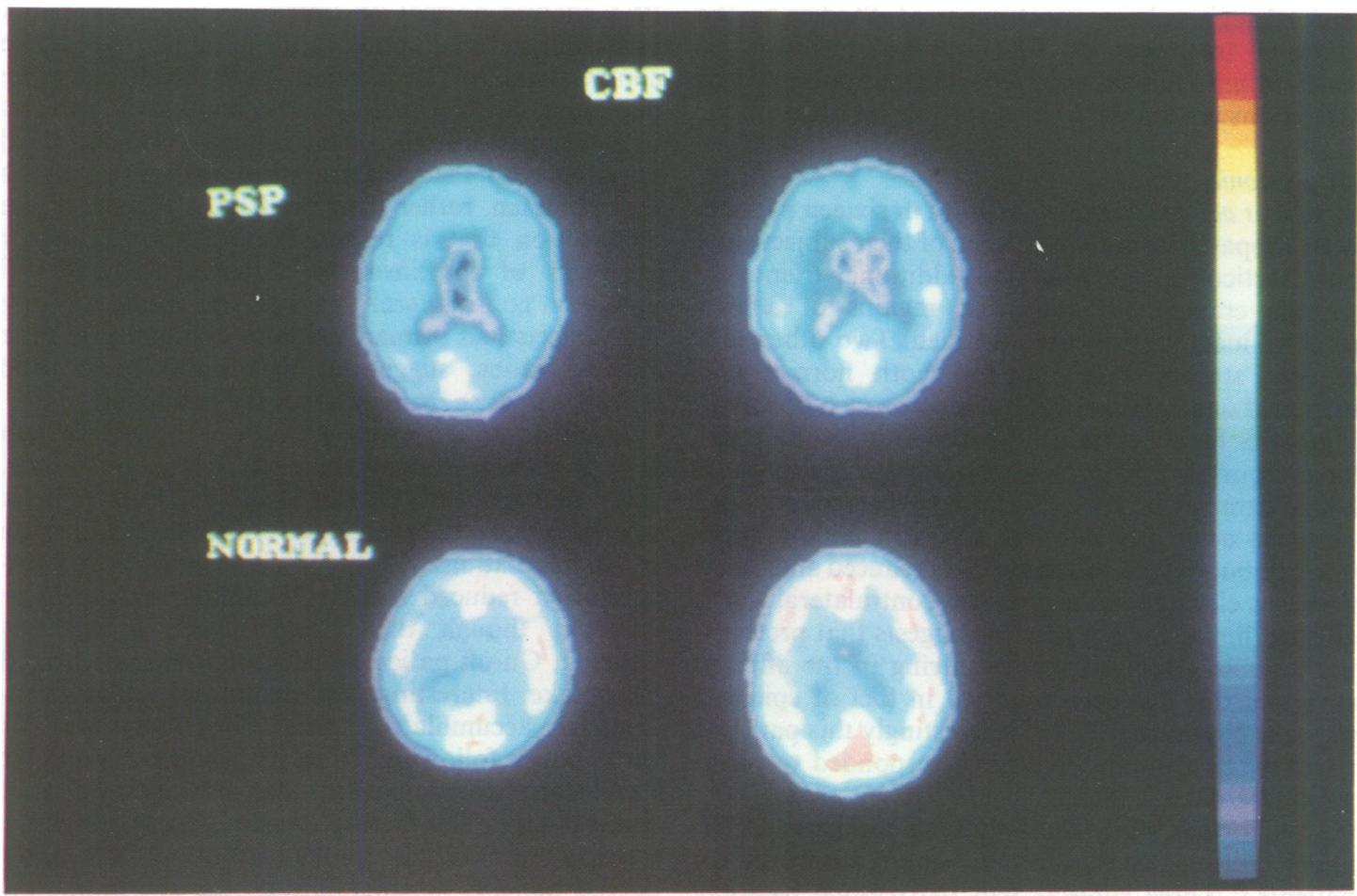

Fig 1 Regional cerebral blood flow in a progressive supranuclear palsy patient and a normal control. There is a global reduction of $\mathrm{rCBF}$ in the PSP subject.

ical details of their individual subjects were not provided; one was subsequently found post mortem to have multiple system atrophy, again emphasising the clinical difficulty in diagnosing this condition.

In summary, PSP appears to be associated with hypometabolism of all cortical regions, particularly frontal cortex, and also basal ganglia, thalamus, and brainstem nuclei. There appears to be sparing of cerebellar function.

\section{(d) Multiple system atrophy (MSA)}

This condition may present as an akinetic rigid syndrome, poorly responsive to levodopa, autonomic failure, and pontocerebellar dysfunction, and is often known as Shy-Drager syndrome (SDS). Pathologically neuronal fall-out and gliosis are found in the basal ganglia, brain-stem and cerebellar nuclei, and the intermediolateral columns of the spinal cord. Anterior horn cell disease and an axonal neuropathy may also be present. MSA is not associated with Lewy body or neurofibrillary tangle formation. Unlike PSP patients intellect is preserved in MSA cases. It remains unclear if the akinetic-rigid and pontocerebellar (OPCA) variants of MSA are part of a spectrum, or if they represent separate conditions.
There are few reports of the use of PET in patients with MSA. Rosenthal et al $^{21}$ studied regional cerebral glucose utilisation in thirty patients with pontocerebellar (OPCA) degeneration. Their subjects had primarily cerebellar degeneration, a minority having evidence of pyramidal dysfunction. Out of thirty, fourteen had a familial disorder. These authors found that locomotor dysfunction correlated better with levels of cerebellar and brainstem hypometabolism, than with the degree of atrophy on CT scan. Preliminary data on six subjects with MSA and a akinetic rigid syndrome have not shown a clear correlation between striatal hypometabolism and locomotor dysfunction. ${ }^{22}$

(e) Wilson's disease (WD)

This recessively-inherited condition is thought to arise from impaired biliary excretion of copper. As a consequence copper is deposited in cerebral grey matter, particularly the striatum, and results in cystic degeneration. CT brain scans generally show cortical atrophy, a minority revealing additional low attenuation lesions in the basal ganglia. ${ }^{23}$ PET scans, however, consistently reveal reduced glucose utilisation in the striatum, the putamen being worst affected.$^{24}$ rCMRGlu is also globally depressed in the cortex, fronto- 
parietal regions being most impaired. Studies on the effect of treatment on PET cerebral measures of function have not yet been reported, although striatal CT lesions are known to be reversible on occasion. ${ }^{23}$

\section{(f) Dystonia}

Stoessl et $a^{25}$ measured rCMRGlu in sixteen patients with idiopathic torticollis. Eleven of their subjects had pure torticollis, and four had additional tremor or writer's cramp. No consistent regions of altered cerebral metabolism were identified. Two other subsequent studies have reported both normal and increased contralateral striatal glucose metabolism in idiopathic focal dystonia.$^{5253}$ Perlmutter and Raichle ${ }^{26}$ have reported a case of post-traumatic paroxysmal hemidystonia whose attacks lasted a few seconds, and occurred every few minutes. CT scan findings were normal, but oxygen utilisation was reduced and blood flow was elevated in the striatum contralateral to the affected limbs. Such a pattern suggests that preferential aerobic glycolysis was occurring in the affected striatum; this has been reported in foci of epilepsia partialis continua (EPC) ${ }^{27}$ Interestingly this patient's paroxysmal dystonia, like EPC, responded to phenytoin treatment.

In a further study these authors measured rCBF under resting conditions in seven hemidystonic patients. $^{{ }^{50}}$ Three subjects had paroxysmal dystonia (two post-traumatic and one familial), while four had idiopathic dystonia. Five out of seven of these patients showed no resting rCBF abnormalities, but two had raised rCBF in the putamen contralateral to their affected limbs. These preliminary studies are encouraging, as they suggest PET is capable of detecting functional abnormalities in some dystonias in the absence of an obvious structural lesion on CT.

\section{(g) Summary}

The patterns of regional cerebral metabolic dysfunction associated with various movement disorders are summarised in table 2 .

\section{Regional neuropharmacological changes in movement disorders}

(a) Parkinson's disease (PD)

${ }^{18} \mathrm{~F}$-6-fluorodopa (F-dopa), when given intravenously, is transported across the blood-brain barrier by the neutral aminoacid carrier and stored as F-dopamine and its metabolites in the terminals of nigro-striatal neurones. ${ }^{28}$ As a consequence, striatal ${ }^{18} \mathrm{~F}$ activity following ${ }^{18} \mathrm{~F}$-dopa administration provides a measure of striatal dopamine storage capacity. Garnett et al ${ }^{29}$ and Nahmias et al ${ }^{30}$ published the first PET reports on striatal ${ }^{18} \mathrm{~F}$-dopa administration. Their subjects had hemiparkinsonism, and were young with early disease.
PET showed normal ${ }^{18} \mathrm{~F}$ uptake in the caudate, but bilaterally reduced uptake in the putamen, the uptake contralateral to the affected limbs being the more depressed. Such a finding indicates that in patients with hemiparkinsonism there is invariably subclinical involvement of the ipsilateral striatum. It also suggests that putamen, rather than caudate, is the site of the dysfunction that is responsible for the locomotor problems of Parkinsonian patients. Reduced ${ }^{18} \mathrm{~F}$ uptake in contralateral putamen was found whether the subjects had primarily tremor or rigidity of their affected limbs, suggesting that both tremor and rigidity can arise from putamenal dysfunction.

Leenders et $a l^{31}$ studied ${ }^{18} \mathrm{~F}$-dopa uptake in two groups of Parkinsonian patients with bilateral disease, one group with early disease and a sustained response to levodopa, and a second severely affected group with on-off fluctuations. All the Parkinson's disease patients showed reduced striatal ${ }^{18} \mathrm{~F}$ uptake compared to controls, though the controls were significantly younger. On-off patients had lowest levels of striatal ${ }^{18} \mathrm{~F}$ uptake. Interestingly, while normal subjects continuously accumulated striatal ${ }^{18} \mathrm{~F}$ activity over the three hours following ${ }^{18} \mathrm{~F}$-dopa administration, the Parkinson's disease patients showed a plateauing of tracer uptake. This finding suggests that although the transport of ${ }^{18} \mathrm{~F}$-dopa into the striatum of Parkinson' $\$$ disease patients remains normal, the ability of thei striatum to store ${ }^{18} \mathrm{~F}$-dopamine is impaired. In second publication, the same authors compared the degree of locomotor dysfunction with the accumula tion of ${ }^{18} \mathrm{~F}$ in the striatum in their Parkinson's disease patients. ${ }^{32}$ Parkinsonian rigidity correlated with $\overrightarrow{0}$ decline in striatal ${ }^{18} \mathrm{~F}$-dopa uptake, but surprisingly Leenders et al did not find a correlation between striatal ${ }^{18} \mathrm{~F}$-uptake and severity of tremor.

The $\mathrm{S}$ or $(+)$ isomer of ${ }^{11} \mathrm{C}$-nomifensine ( $\left.{ }^{11} \mathrm{C}-\mathrm{NMF}\right)$ binds to sites of dopamine re-uptake on the nigrostriatal nerve terminals in the caudate and putamen, and to sites of noradrenaline re-uptake sites in the ventral thalamus. ${ }^{33}$ Using a racemic mixture of ${ }^{11} \mathrm{C}$ NMF, Tedroff $e t a^{34}$ studied striatal tracer uptake in six Parkinson's disease patients and seven contro

Table 2 Changes in regional cerebral metabolism associated with movement disorders

\begin{tabular}{|c|c|c|c|c|c|c|}
\hline & $\begin{array}{l}\text { Parkinson's } \\
\text { disease } \\
\text { (uni) }\end{array}$ & $\begin{array}{l}\text { Parkinson's } \\
\text { disease } \\
\text { (bilat) }\end{array}$ & $H D$ & $P S P$ & $M S A$ & $W D$ \\
\hline $\begin{array}{l}\text { Caudate } \\
\text { Putamen } \\
\text { Cerebellum } \\
\text { Thalamus } \\
\text { Frontal }\end{array}$ & $\begin{array}{l}\mathrm{CL} \uparrow \text { or } \mathbf{N} \\
\mathbf{C L} \uparrow \text { or } \mathbf{N} \\
\mathbf{N} \\
\mathbf{N}\end{array}$ & $\begin{array}{l}\mathbf{N} \text { or } \downarrow \\
\mathbf{N} \text { or } \downarrow \\
\mathbf{N} \\
\mathbf{N}\end{array}$ & $\stackrel{\downarrow \downarrow}{\downarrow}$ & $\underset{\downarrow}{\downarrow}$ & $\begin{array}{l}\downarrow \\
\downarrow \\
N\end{array}$ & $\begin{array}{l}\downarrow \\
\pm \downarrow \\
\mathbf{N} \\
\mathbf{N}\end{array}$ \\
\hline cortex & $\mathrm{CL} \downarrow$ & $\downarrow$ & $\downarrow$ & $\downarrow$ & $\mathbf{N}$ & $\downarrow$ \\
\hline
\end{tabular}

$\mathrm{CL}=$ contralateral. $\mathrm{N}=$ normal 


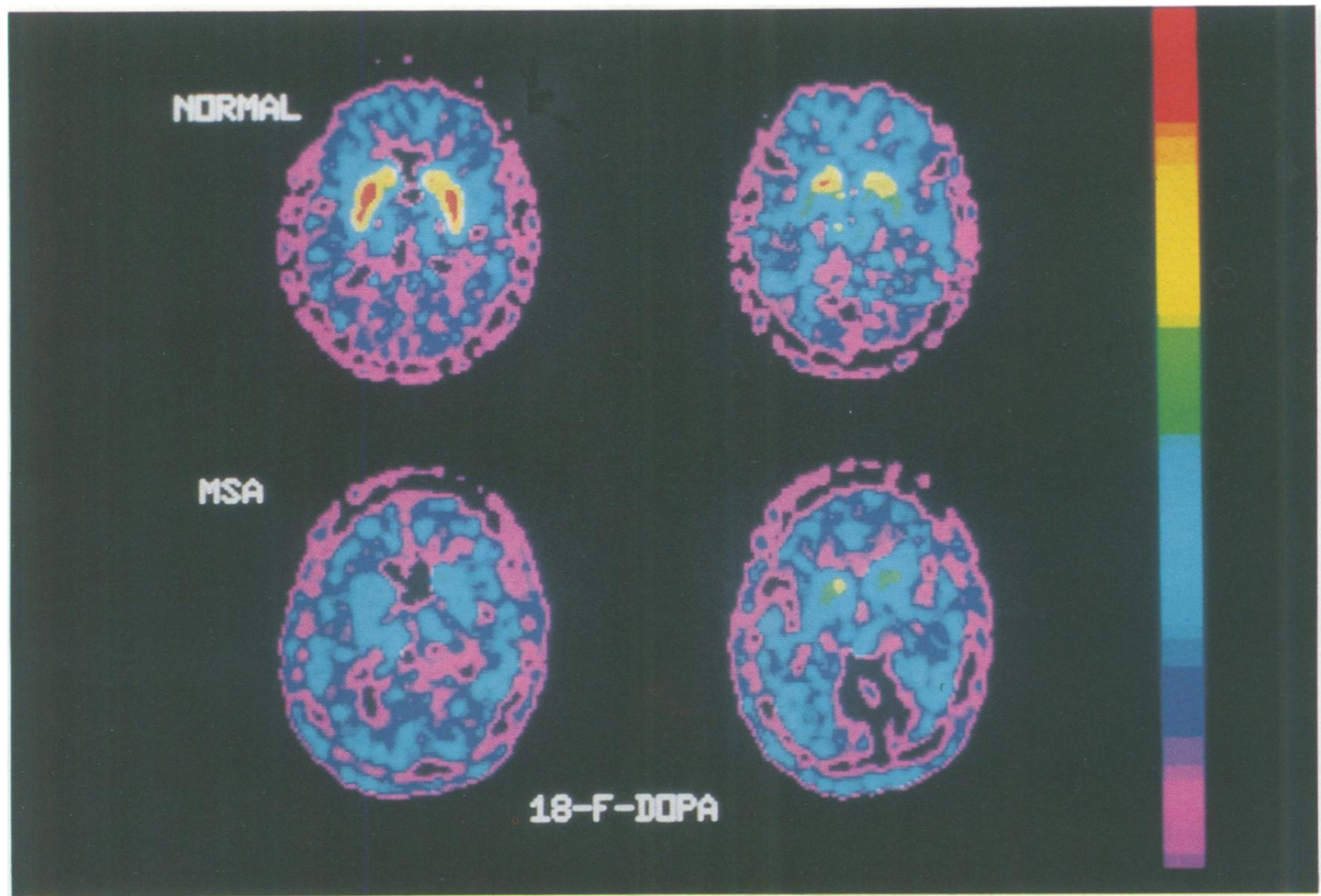

Fig 2 Regional cerebral ${ }^{18} \mathrm{~F}$-Dopa uptake in a normal subject and a patient with multiple system atrophy (ShyDrager syndrome). High ${ }^{18} \mathrm{~F}$ uptake can be seen in the caudate and putamen of the normal subject, but uptake is impaired in the MSA subject.

subjects. The three younger Parkinson's disease subjects appeared to have reduced striatal "C-NMF uptake compared to controls of a similar age, and the two primarily hemiparkinsonian subjects showed a greater reduction of "C-NMF uptake in striatum contralateral to their affected limbs. However, the specific signal from racemic "C-NMF was small, making discrimination between Parkinson's disease patients and controls difficult. A recent study, using pure $(+)$ "C-NMF, has shown a significant fall in both caudate and putamen tracer uptake in Parkinson's disease compared with age-matched controls. ${ }^{35}$ This finding is of interest as it implies that not only do Parkinsonian patients fail to store dopamine adequately in the striatum, but they also are unable to reaccumulate it normally after it is released. An inability to re-accumulate dopamine in the striatum may contribute to the development of the on-off phenomenon in Parkinson's disease, as in this situation a sustained clinical response to levodopa will require a constant delivery of the drug to the striatum. Several studies have demonstrated that on-off responses to oral levodopa in Parkinson's disease can be improved by the use of intravenous infusions of levodopa. ${ }^{36}$

Post-synaptic striatal dopamine $D_{2}$ receptors can be imaged with PET tracers such as 11C-methylspiperone ( ${ }^{11} \mathrm{C}$-MSP), ${ }^{18} \mathrm{~F}$-fluspiperone, and ${ }^{76} \mathrm{Br}$-bromospiperone $\left({ }^{6} \mathrm{Br}\right.$-BSP). Leenders et $a l^{37}$ first demonstrated a similar striatal distribution of ${ }^{18} \mathrm{~F}$-dopa and ${ }^{11} \mathrm{C}$-MSP in a normal volunteer. They then studied striatal " $\mathrm{C}$ MSP uptake in four untreated and five treated PD patients. ${ }^{38}$ The untreated patients had similar striato:cerebellar $(\mathrm{s} / \mathrm{c})$ ratios of tracer uptake to agematched controls, suggesting normal levels of striatal $D_{2}$ receptors were present. The treated Parkinson's disease subjects had reduced tracer s/c ratios, implying that levodopa therapy may have led to down-regulation of their striatal $D_{2}$ receptors. Rutgers et al ${ }^{39}$ studied striatal " C-MSP uptake in thirteen hemiparkinsonian patients. They found that striatal tracer uptake was symmetrical suggesting that levels of $D_{2}$ receptors are preserved in Parkinson's disease. Hagglund $e t$ al $^{\text {p0 }}$ also reported normal striatal "CMSP binding in six Parkinsonian patients. Those patients who were primarily hemiparkinsonian again 


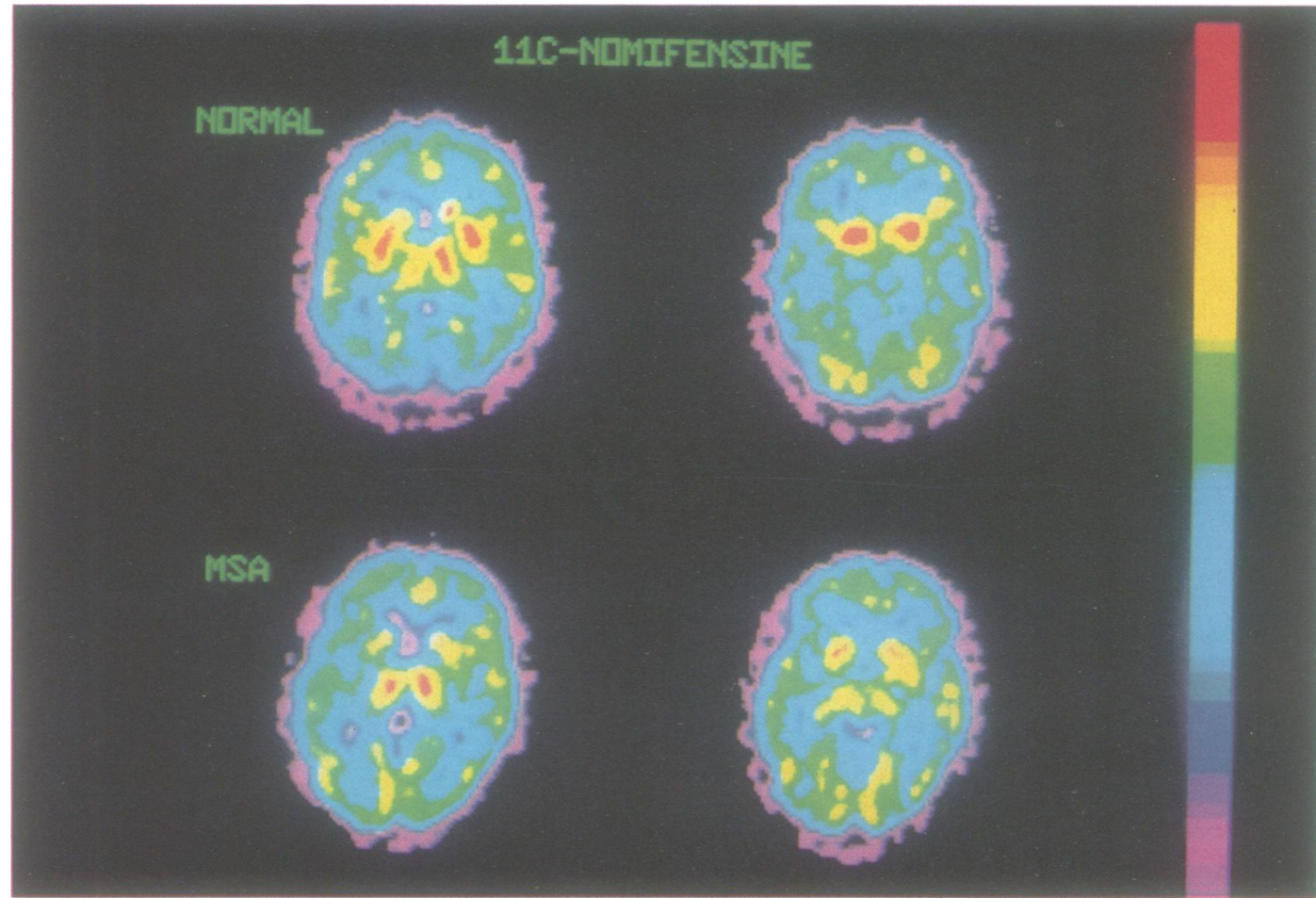

Fig 3 Regional cerebral "C-nomifensine biding in a normal subject and a patient with multiple system atrophy (Shy Drager syndrome). High "C uptake is seen in the caudate, putamen, and thalamus of the normal subject. Impaired "C uptake is seen in the striatum of the MSA patient, but uptake is preserved in the thalamus.

showed no consistent asymmetry in striatal " $\mathrm{C}$-MSP binding. From these studies it can be concluded that although nigro-striatal fibres are damaged in Parkinson's disease, post-synaptic $D_{2}$ receptors are preserved, explaining the good response of Parkinson's disease patients to levodopa. Further studies are required to establish whether levodopa therapy truly leads to down-regulation of $D_{2}$ receptors.

\section{(b) MPTP-induced Parkinsonism}

MPTP (N-methyl-4-phenyl-1,2,3,6-tetrahydropyridine), when given intravenously, crosses the bloodbrain barrier and is converted to $\mathrm{MPP}^{+}$by monoamine oxidase $\mathrm{B}$ in glial tissue. $\mathrm{MPP}^{+}$is then transported into dopaminergic neurons via the dopamine re-uptake mechanism where it results in neuronal death and levodopa responsive Parkinsonism. Hartvig et $a^{41}$ have studied the kinetics of distribution of " $\mathrm{C}$-MPTP in primate brain. This tracer is rapidly taken up and retained in cortex, striatum, thalamus, and mid-brain. The MAO-A inhibitor, clorgyline, has no effect on "C-MPTP uptake but pargyline, a non-specific MAO-A and B inhibitor, induces rapid "C-MPTP washout. This suggests that uptake and conversion of MPTP to $\mathrm{MPP}^{+}$occurs within minutes in glial tissue, and it is $\mathrm{MPP}^{+}$and not MPTP that is retained by brain tissue. If MPTP to $\mathrm{MPP}^{+}$conversion is blocked by pargyline, the "CMPTP is rapidly washed out. Nomifensine, a dopamine re-uptake site blocker, has no immediate effect on "C-MPTP uptake kinetics. This implies that " $\mathrm{C}$ activity is initially trapped as glial rather than neuronal "C-MPP", and that neuronal $\mathrm{MPP}^{+}$ accumulation via the dopamine re-uptake pathway is a far slower process.

Chiueh et $a l^{42}$ very elegantly used MPTP treated monkeys to validate PET measurements of striatal "Fdopa uptake as a measure of striatal dopamine storage capacity. In vivo primate striatal ${ }^{18} \mathrm{~F}$-dopa uptake was reduced and paralleled postmortem striatal dopamine content, and correlated inversely with rigidity. MPTP exposed human subjects have also been shown to have reduced striatal ${ }^{18} \mathrm{~F}$-dopa uptake. ${ }^{43}$

Perlmutter et al, ${ }^{44}$ using PET and ${ }^{18} \mathrm{~F}$-fluspiperone, have reported up-regulation of striatal $\mathrm{D}_{2}$ receptors in an MPTP-exposed patient. This implies that in man, while MPTP attacks nigrostriatal dopaminergic neurons, it spares striatal efferents. Leenders $e t a^{s 1}$ 
confirmed this by unilaterally lesioning a primate with MPTP. The affected striatum showed reduced uptake of "C-nomifensine, a marker of dopamine re-uptake sites on nigrostriatal terminals, but showed raised "Craclopride binding, a marker of post-synaptic $D_{2}$ receptor integrity.

(c) Progressive supranuclear palsy (PSP)

Both pre- and post-synaptic dopaminergic systems have been investigated with PET in this poorly levodopa responsive akinetic rigid syndrome. Striatal ${ }^{18} \mathrm{~F}$-dopa uptake in PSP subjects is diminished to the same degree as in levodopa-responsive Parkinson's disease, ${ }^{19}$ and correlates with the degree of frontal cortical hypometabolism present in these patients. Contrary to the findings in Parkinson's disease, levels of striatal $\mathrm{D}_{2}$ receptors appear to be diminished in PSP. Baron et $a l^{45}$ compared striatal ${ }^{76} \mathrm{Br}$-bromospiperone (BSP) binding in seven PSP patients and seven age-matched control subjects. BSP is a $D_{2}$ receptor marker, and striato-cerebellar ratios of the uptake of this tracer at 4 hours were significantly depressed in PSP subjects. Such a finding would in part explain the lack of response of PSP subjects to levodopa.

\section{(d) Multiple system atrophy (MSA)}

These patients are poorly responsive to levodopa. The integrity of the presynaptic dopaminergic system in MSA patients has been studied with PET. ${ }^{35}{ }^{46}$ Figure 2 shows PET images of striated ${ }^{18} \mathrm{~F}$-dopa uptake in a normal subject and a patient with multiple system atrophy. Both Parkinson's disease and MSA patients show impairment of striatal uptake of ${ }^{18} \mathrm{~F}$ activity following ${ }^{18} \mathrm{~F}$-dopa administration. Putamen function is equally severely affected in both these conditions, but unlike Parkinson's disease, where caudate function is relatively spared, ${ }^{29} 3050$ of MSA subjects show equally impaired caudate and putamen ${ }^{18} \mathrm{~F}$-dopa uptake. ${ }^{35}$ The involvement of caudate in MSA, and relative sparing of caudate in Parkinson's disease, is likely to reflect the different pathologies of these two conditions. In MSA striatal degeneration occurs, while in Parkinson's disease the substantia nigra compacta is primarily involved. Although both caudate and putamen are severely affected in MSA, it is putamen rather than caudate dysfunction that correlates with locomotor disability in MSA patients. ${ }^{3546}$ Such a finding is in line with current theories of basal ganglia function. ${ }^{47}$ The putamen receives direct input from the supplementary motor cortex, while the caudate receives input from frontal association areas. As such the caudate is less likely to play a direct role in motor control.

Figure 3 shows PET images of $(+)-{ }^{11} \mathrm{C}-$-nomifeusine uptake in a normal subject and a MSA patient.
Striatal " $\mathrm{C}$-nomifensine binding is diminished in MSA $^{3546}$ suggesting that fall-out of dopamine reuptake sites occurs in parallel with diminished striatal dopamine storage capacity. Such a finding may simply reflect a loss of nigro-striatal nerve terminals. To date no data on post-synaptic dopamine $D_{2}$ receptor status in MSA have been reported. In view of the poor levodopa responsiveness of these patients, and the presence of striatal degeneration at post-mortem, one would expect a low density of striatal D2 sites to be present.

\section{(e) Huntingdon's disease (HD)}

Leenders $e t$ al $^{12}$ studied the integrity of the pre- and post-synaptic dopaminergic system in one case of early Huntingdon's disease. Their subject had normal striatal ${ }^{18} \mathrm{~F}$-dopa uptake, implying an intact nigrostriatal pathway was present, but reduced striatal ${ }^{11} \mathrm{C}$ methylspiperone binding, suggesting a reduced density of post-synaptic D2 dopamine receptors had resulted. These findings would fit in with the known pathology of HD where fall-out of spiny striatal neurones is seen, but the nigro-striatal pathway is spared. Hagglund et $a l^{40}$ have examined striatal " $\mathrm{C}$ MSP binding in a case of HD. These authors also found reduced "C-MSP striatal uptake in their patient.

\section{(f) Dystonia}

This is a highly heterogeneous condition and may result from lesions in the striatum, pallidum, ventral thalamus, and mid-brain. In idiopathic torsion dystonia, which is frequently familial, it is common to find no abnormalities either at post-mortem, or on structural imaging. Leenders $e t a^{48}$ have PET scanned a series of six dystonic patients. Three had idiopathic hemidystonia, one acquired hemidystonia, and two had torticollis. The four hemidystonic subjects showed impaired contralateral striatal ${ }^{18} \mathrm{~F}$-Dopa uptake, and the two subjects with torticollis had bilaterally impaired striatal ${ }^{18} \mathrm{~F}$-dopa uptake. The hemidystonic patients were not typical of idiopathic torsion dystonia, however, in that all subjects had extrapyramidal rigidity between dystonic spasms. Further studies are required to determine if functional lesions of the nigrostriatal pathway are a consistent finding in idiopathic torsion dystonia.

\section{(g) Summary}

The patterns of striatal dysfunction of the dopaminergic system associated with various movement disorders are summarised in table 3.

\section{The future of PET in movement disorders}

This paper has reviewed the potential of PET for identifying the varying patterns of disruption of 
Table 3. The status of the dopaminergic system in movement disorders

\begin{tabular}{lllll}
\hline Striatum & $\begin{array}{l}\text { Parkinson's } \\
\text { disease }\end{array}$ & PSP & HD & MSA \\
\hline $\begin{array}{l}\text { Dopamine storage } \\
\text { Dopamine reuptake }\end{array}$ & $\downarrow$ & $\downarrow$ & $\mathrm{N}$ & $\downarrow$ \\
$\mathrm{D}_{2}$ receptors & $\mathrm{N}$ & $\downarrow$ & $\downarrow$ & $\downarrow$ \\
\hline
\end{tabular}

$\mathbf{N}=$ normal.

regional cerebral metabolism and dopaminergic function associated with movement disorders. PET is a highly sensitive technique, and can detect reduced striatal metabolism in Huntingdon's disease and Wilson's disease, and reduced frontal hypometabolism in Parkinson's disease and progressive supranuclear palsy, in the absence of CT lesions. It can also help to distinguish Parkinson's disease from other akinetic -rigid syndromes, such as PSP and MSA, by detecting differential loss of nigro-striatal dopaminergic neurons from the caudate and putamen, and by detecting fall-out of striatal post-synaptic $D_{2}$ receptors. Having said this, to date there has been little pathological validation of the use of PET for distinguishing between the various classes of movement disorder. It is important that in the future postmortem findings are correlated with the present wealth of PET data.

The role of PET in detecting sub-clinical disease has only been fully exploited in Huntingdon's disease. Mazziotta et al, ${ }^{14}$ and Hayden et al,$^{13}$ have demonstrated that PET and DNA polymorphism studies have a $38 \%-91 \%$ concordance rate in detecting abnormalities in at-risk subjects for HD. In the future it may be possible to detect sub-clinical Parkinson's disease, and to detect abnormalities of basal ganglia function in relatives of patients with idiopathic dystonia.

With the improved resolution of current PET scanners, and their multi-slice capabilities, cerebral activation studies are now a great deal easier to perform. It is possible to investigate the effects of Parkinson's disease and dystonia on normal patterns of activation of central and cortical structures by monitoring regional cerebral blood flow changes while a patient performs different motor paradigms, and is exposed to different sensory stimuli. In this way more will be learnt about the functional connections of the basal ganglia, thalamus, sensorimotor cortex, and cortical association areas, and how these connections are impaired in movement disorders. Preliminary work along these lines has been performed by Perlmutter and Raichle in dystonic patients. ${ }^{50}$ Their findings suggest that abnormal activation of the sensorimotor cortex may occur in dystonia.

Finally nearly all PET studies of pharmacological on movement disorders have concerned the dopamin- $z$ ergic system. With the current availability of PET $\mathbb{C}$ markers of the opiate and serotonergic systems, and in the future glutamatergic and peptidergic markers, our $\stackrel{\text { ? }}{=}$ understanding of the neuropharmacological changes. $\vec{\theta}$ associated with movement disorders is likely to 0 expand rapidly.

\section{References}

1 Kuhl DE, Metter EJ, Riege WH, Markham CH. Patterns of $\stackrel{\overline{\bar{c}}}{+}$ cerebral glucose utilisation in Parkinson's disease and Hunting- $\square$ don's disease. Ann Neurol 1984;15:S119-S125.

2 Kuhl DE, Metter EJ, Benson DF, et al. Similarities of cerebral $\frac{\bar{\sigma}}{\bar{D}}$ glucose metabolism in Alzheimer's and Parkinsonian dementia. J Cereb Blood Flow Metabol 1985;5:S169-70.

3 Rougemont D, Baron JC, Collard P, et al. LCMRGlu in untreated vه and treated Parkinson's disease. J Cereb Blood Flow Metabol os 1983;3:S504-S505.

4 Wooten GF, Collins RC. Metabolic effects of unilateral lesions of the substantia nigra. $J$ Neurosci 1981;1:285-91.

5 Miletich RS, Chan T, Gillespie M, Di Chiro G, Stein S. Contralateral basal ganglia metabolism is abnormal in hemiparkinsonian patients. An FDG-PET study. Neurology 1988;38금 (Supp):260.

6 Wolfson LI, Leenders KL, Brown LL, Jones T. Alterations of $\mathrm{N}$ Regional Cerebral Blood Flow and Oxygen Metabolism in $\backsim$ Parkinson's Disease. Neurology 1985;35:1399-405.

7 Perlmutter JS, Raichle ME. Regional blood flow in hemipark sonianism. Neurology 1985;35:1127-34.

8 Leenders KL, Wolfson L, Gibbs JM, et al. The effects of L-dopa regional cerebral blood flow and oxygen metabolism in patierts 음 with Parkinson's disease. Brain 1988;108:171-91.

9 Kuhl DE, Phelps ME, Markham CH, et al. Cerebral metabolis and atrophy in Huntingdon's disease determined by ${ }^{18}$ FDG afi computed tomographic scans. Ann Neurol 1982;12:425-34. $\leq \frac{1}{\leq}$

10 Hayden MR, Martin WRW, Stoessl AJ, et al. Positron Emissifri Tomography in the early diagnosis of Huntingdon's Disease Neurology 1986;36:888-94.

11 Young AB, Penney JB, Starosta-Rubinstein S, et al. PET scan investigations of Huntingdon's disease: cerebral metabolic $\bigcirc$ correlates of neurological features and functional decline. Ann Neurol 1986;20:296-303.

12 Leenders KL, Frackowiak RSJ, Quinn N, Marsden CD. Brain 용 Energy Metabolism and Dopaminergic Function in Hunting- 음 don's Disease measured in vivo using Positron Emission @ Tomography. Movement Disorders 1986;1:69-77.

13 Hayden MR, Hewitt J, Martin WRW, Clark C, Amman W. 윽 Studies in Persons at risk for Huntingdon's Disease. $N$ Engl J Med 1987;317:382-3.

14 Mazziotta JC, Phelps ME, Pahl JJ, et al. Reduced cerebral glucose metabolism in asymptomatic subjects at risk for Huntingdon's Disease. N Engl J Med 1987;316:357-62.

15 Suchowersky O, Hayden MR, Martin WRW, et al. Cerebral metabolism of glucose in benign hereditary chorea. Movement Disorders 1986;1:33-45.

16 Guttman M, Lang AE, Garnett ES, et al. Regional Cerebral Glucose Metabolism in SLE Chorea: Further evidence that Striatal Hypometabolism is not a correlate of Chorea. Movement Disorders 1987;2:201-10.

17 Pahl JJ, Mazziotta JC, Cummings J, et al. Positron Emission Tomography in Tardive Dyskinesia and Huntington's Disease. J Cereb Blood Flow Metabol 1987;7:S373.

18 D'Antona R, Baron JC, Samson Y, et al. Subcortical dementia. N Frontal cortex hypometabolism detected by positron tomo- $\mathrm{N}$ graphy in patients with progressive supranuclear palsy. Brain $\mathrm{N}$ 1985;108:785-99. 
19 Leenders KL, Frackowiak RSJ, Lees AJ. Steele-Richardson-Olszewski syndrome, Brain Energy Metabolism, Blood Flow, and Fluorodopa uptake, measured by Positron Emission Tomography. Brain 1988;111:615-30.

20 Foster NL, Gilman S, Berent S, et al. Cerebral Hypometabolism in Progressive Supranuclear Palsy studied with Positron Emission Tomoraphy. Ann Neurol 1988;24:399-406.

21 Rosenthal G, Gilman S, Koeppe RA, et al.. Motor dysfunction in Olivopontocerebellar Atrophy is related to Cerebral Metabolic Rate studied with Positron Emission Tomography. Ann Neurol 1988;24:414-9.

22 Eidelberg D, Sidtis JJ, Moeller JR, et al. The metabolic anatomy of Typical and Atypical Parkinsonism: Complementary ${ }^{18} \mathrm{~F}$ Fluorodeoxyglucose and ${ }^{18} \mathrm{~F}$-Fluorodopa Positron Emission Tomography Studies. Ann Neurol 1988;23 (Suppl):S45.

23 Williams FJB, Walshe JM. Wilson's disease. An analysis of the cranial computerised tomographic appearances found in 60 patients and the changes in response to treatment with chelating agents. Brain 1981;104:735-52.

24 Hawkins RA, Mazziotta JC, Phelps ME. Wilson's Disease studied with FDG and Positron Emission Tomography. Neurology 1987;37:1707-11.

25 Stoessl AJ, Martin WRW, Clark C, et al. PET studies of cerebral glucose metabolism in idiopathic torticollis, Neurology 1986; 36:653-7.

26 Perlmutter JS, Raichle ME. Pure hemidystonia with basal ganglion abnormalities in Positron Emission Tomography. Ann Neurol 1984;15:228-233.

27 Cowan JMA, Rothwell JC, Wise RJS, Marsden CD. Electrophysidological and positron emission tomography studies in a patient with cortical myoclonus, epilepsia partialis continua, and motor epilepsy. J Neurol Neurosurg Psychiatry 1986;49:796-807.

28 Firnau G, Sood S, Chirakal R, Nahmias C, Garnett ES. Cerebral metabolism of 6-(18F)fluoro-L-3, 4-dihydroxyphenylalanine in the primate. J Neurochem 1987;48:1077-82.

29 Garnett ES, Nahmias C, Firnau G. Central dopaminergic pathways in hemiparkinsonism examined by positron emission tomography. Can J Neurol Sci 1984;11:174-9.

30 Nahmias C, Garnett ES, Firnau G, Lang A. Striatal dopamine distribution in Parkinsonian patients during life. J Neurol Sci 1985;69:223-30.

31 Leenders KL, Palmer AJ, Quinn N, et al. Brain dopamine metabolism in patients with Parkinson's disease measured with Positron Emission Tomography. J Neurol Neurosurg Psychiatry 1986;49:853-60.

32 Leenders KL, Palmer A, Turton D, et al. Dopa uptake and dopamine receptor binding visualised in the human brain in vivo. In: Fahns S, Marsden CD, Jenner $P$, Teychenne $P$, eds. Recent Developments in Parkinson's Disease. New York: Raven Press, 1986:103-113.

33 Toumisto J. Nomifensine and its derivatives as possible tools for studying amine uptake. Eur J Pharmacol 1977;42:101-6.

34 Tedroff J, Aquilonius SM, Hartvig P, et al. Monoamine reuptake sites in the human brain evaluated in vivo by means of "C-nomifensine and positron emission tomography: the effects of age and Parkinson's disease. Acta Neurol Scand 1988;77: 192-201.

35 Brooks DJ, Salmon EP, Mathias CJ, et al. The integrity of the dopaminergic system in patients with multiple system atrophy and pure autonomic failure studied with PET. In: Berardelli A, Benecke R, Manfredi M, Marsden CD, eds. Motor Disturbances II. Academic Press. (in press).

36 Nutt J, Woodward WR. Levodopa pharmokinetics and pharmodynamics in fluctuating Parkinsonian patients. Neurology 1986;
36:739-44.

37 Leenders KL, Herold S, Books DJ, et al. Pre-synaptic and postsynaptic dopaminergic system in human brain. Lancet 1984; ii: $110-1$.

38 Leenders KL, Herold S, Palmer AJ, et al. Human cerebral dopamine system measured in vivo using PET. J Cereb Blood Flow Metabol 1985;5:S157-S158.

39 Rutgers AWF, Lakke JPWF, Paans AMJ, Vaalburg W, Korf J. Tracing of dopamine receptors in hemiparkinsonism with positron emission tomography. J Neurol Sci 1987;80:237-48.

40 Hagglund J, Aquilonius SM, Eckernas SA, et al. Dopamine receptor properties in Parkinson's disease and Huntingdon's chorea evaluated by positron emission tomography using " $\mathrm{C}$ methyl-spiperone. Acta Neurol Scand 1987;75:87-94.

41 Hartvig P, Larsson BS, Lindberg BS, et al. Influence on monoamine oxidase inhibitors and a dopamine re-uptake blocker on the distribution of "C-MPTP in the head of the rhesus monkey. Acta Neurol Scan 1986;74:10-6.

42 Chiueh CC, Firnau G, Burns RS, et al. Determination of visualisation of damage to striatal dopaminergic terminals in MPTP induced Parkinsonism by $\left[{ }^{18} \mathrm{~F}\right]$-labelled 6-Fluoro-LDopa and Positron Emission Tomography. In: Yahr MD, Bergmann .KJ, eds. Advances in Neurology. 45. Parkinson's Disease. New York: Raven, 1987:167-70.

43 Calne DB, Langston JW, Martin WRW, et al. Positron emission tomography after MPTP: observations relating to the cause of Parkinson's Disease. Nature 1985;317:246-8.

44 Perlmutter JS, Kilbourn MR, Raichle ME, Welch MJ. MPTP induced up-regulation of in-vivo dopaminergic radioligand receptor binding in humans. Neurology 1987;37:1575-9.

45 Baron JC, Maziere B, Loc'h C, et al. Loss of striatal (76Br) bromospiperone binding sites demonstrated by positron tomography in progressive supranuclear palsy. $J$ Cereb Blood Flow Metabol 1986;6:131-6.

46 Brooks DJ, Salmon EP, Bannister R, Mathias CJ, Frackowiak RSJ. The integrity of the dopaminergic system in Multiple System Atrophy and Pure Autonomic Failure studied with PET. In: Crossman AR, Sambrook MA, eds. Neural Mechanisms in Disorders of Movement. London: John Libbey, 1989:399-405.

47 Alexander GD, De Long MR, Strick PL. Parallel organisation of functionally segregated circuits linking basal ganglia and cortex. Ann Rev Neurosci 1986;9:357-82.

48 Leenders KL, Quinn N, Frackowiak RSJ, Marsden CD. Brain dopaminergic system studied in patients with dystonia using positron emission tomography. Adv Neurol 1988;50.

49 Young AB, Penney JB, Starosta-Rubinstien S, et al. Normal caudate glucose metabolism in persons at risk for Huntingdon's Disease. Arch Neurol 1987;44:254-7.

50 Perlmutter JS, Raichle ME. Regional cerebral blood flow in Dystonia: An exploratory study. In: Fahn S, et al, eds. Advances in Neurology Vol 50, Dystonia 2. New York: Raven Press, 1988:255-64.

51 Leenders KL, Aquilonius SM, Bergstrom K, et al. Unilateral MPTP lesion in a rhesus monkey: effects on the striatal dopaminergic system measured in vivo with PET using various novel tracers. Brain Res 1988;445:61-7.

52 Chase TN, Tamminga CA, Burrows H. Positron emission tomographic studies of regional cerebral glucose metabolism in idiopathic dystonia. In: Fahn S, et al, eds. Adv Neurol 50. Dystonia 2. New York: Raven Press, 1988: 237-41.

53 Gilman S, Junck L, Young AB, et al. Cerebral metabolic activity in idiopathic dystonia studied with positive emission tomography. In: Fahn S, et al, eds. Adv Neurol 50. Dystonia 2. New York: Raven Press, 1988:231-6. 